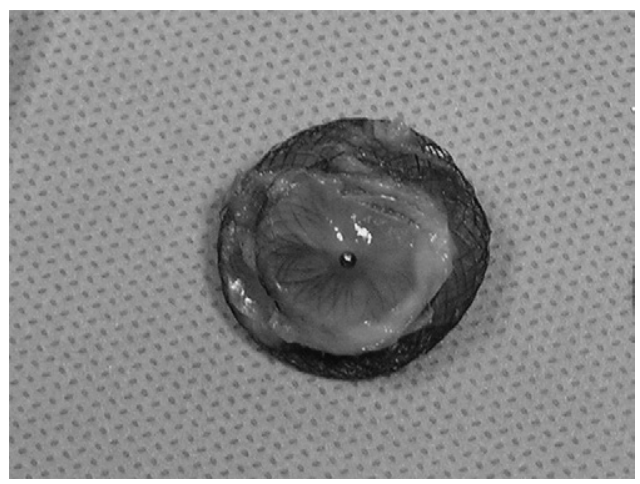

Figure 2. The removed Amplatzer device.

mortality and morbidity. Percutaneous closure is growing rapidly, principally because of the patient's, family's, and pediatric cardiologist's desire for a less invasive procedure. Considering the increase in the number of procedures, a long-term follow-up is necessary to evaluate the safety of mechanical occluders at long term. Our case report described a complication that occurred 13 months after the percutaneous procedure. The literature includes other authors reporting delayed heart perforation by the occluder device ${ }^{5}$, hence this patient's need for long-term echocardiographic follow-up to made an early diagnosis of device failure and prevent emergency surgical intervention. Finally, we conclude that patients should be informed of the actual early and long-term results of surgical repair and percutaneous approach to allow an informed decision.

\section{References}

1. Berger F, Vogel M, Alexi-Meskishvili V, Lange P. Comparison of results and complications of surgical and Amplatzer device closure of atrial septal defects. J Thorac Cardiovasc Surg. 1999;118:674-8.

2. Murphy JG, Gersh BJ, McGoon MD, Mair DD, Porter CJ, Ilstrup DM, et al. Long-term outcome after surgical repair of isolated atrial septal defect. Follow-up at 27 to 32 years. N Engl J Med. 1990 13;323:1645-50.

3. King TD, Mills NL. Secundum atrial septal defect: nonoperative closure during cardiac catheterization. JAMA. 1976;235:2506-9.

4. Contrafouris CA, Chatzis AC, Giannopoulos NM, Milonakis M, Kousi $\mathrm{T}$, Kirvassilis G, et al. Emergency surgical intervention for runaway atrial septal defect closure devices: a word of caution. J Thorac Cardiovasc Surg. 2006;132:1234-5.

5. Teoh K, Wilton E, Brecker S, Jahangiri M. Simultaneous removal of an Amplatzer device from an atrial septal defect and the descending aorta. J Thorac Cardiovasc Surg. 2006;131:909-10.

\title{
Complicated acute type B aortic dissection with involvement of an aberrant right subclavian artery and rupture of a thoracoabdominal aortic aneurysm, Crawford type I: Successful emergency endovascular treatment
}

Victor X. Mosquera, MD, ${ }^{\text {a }}$ Milagros Marini, MD, $\mathrm{PhD},{ }^{\mathrm{b}}$ Fernando Rodríguez, $\mathrm{MD}{ }^{\mathrm{a}}$ Ignacio Cao, MD, and Alberto Juffé, MD, PhD, ${ }^{\mathrm{a}}$ A Coruña, Spain

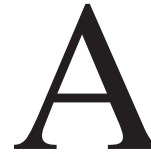

lthough an aberrant right subclavian artery (ARSA) is the most common abnormality of aortic arch development, it is an unusual entity to encounter associated with thoracic aortic dissection. We report the successful endovascular treatment of this association in a critically ill patient.

From the Departments of Cardiothoracic Surgery and Interventional Ra-

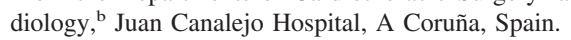

Received for publication June 3, 2007; accepted for publication June 21, 2007.

Address for reprints: Victor X. Mosquera, MD, Cardiac Surgery Department, Hospital Juan Canalejo, As Xubias n ${ }^{\circ} 84$, CP 15006, A Coruña, Spain (E-mail:vxmr@canalejo.org; vxmr@yahoo.es).

J Thorac Cardiovasc Surg 2007;134:1055-7

$0022-5223 / \$ 32.00$

Copyright $\odot 2007$ by The American Association for Thoracic Surgery doi:10.1016/j.jtcvs.2007.06.024

\section{Clinical Summary}

An 80-year-old man was referred to our institution with the diagnosis of an acute aortic Stanford type $\mathrm{B}$ dissection (Figure 1, A). The computed tomographic scan images also showed a thoracoabdominal aortic aneurysm extending from an ARSA (Figure 1, $B$ ) to the esophageal hiatus (Crawford type I).

Because of persistent back pain despite correct intravenous treatment, a new computed tomographic scan was repeated 8 hours later, revealing progression of the aortic dissection and the appearance of a left-sided hemothorax. Blood analysis also showed a fall of 10 points in the hematocrit value.

Because of the patient's critical status and high surgical risk, emergency endovascular treatment was indicated. Notwithstanding, the procedure was technically demanding, because the endograft had to be deployed while avoiding occlusion of the ARSA. However, the diameter of the aortic aneurysm distal to the origin 


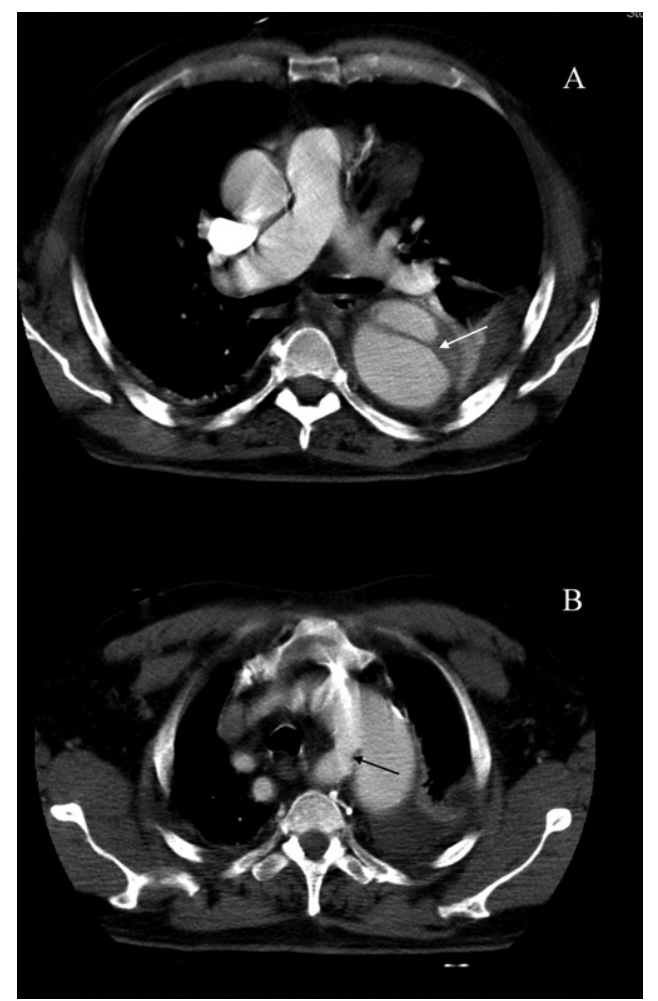

Figure 1. Contrast-enhanced slides of computed tomographic image. Axial section of the thoracoabdominal aneurysm. A, Aortic type B dissection (white arrow) with the false lumen (posterior) compressing the true lumen (anterior). B, Origin of the ARSA (black arrow).

of the ARSA was greater than $46 \mathrm{~mm}$, which is the maximum diameter amenable for the standard Medtronic Valiant thoracic endograft (Medtronic, Inc, Santa Rosa, Calif). Therefore, the deployment of the endoprosthesis was adjusted to the origin of the ARSA, where the thoracic aneurysm had a neck of $42 \mathrm{~mm}$. A Valiant endograft, $160 \mathrm{~mm}$ in length and $46 \mathrm{~mm}$ in diameter, was deployed at the level of ARSA origin, so that its floppy FreeFlo straight portion (Figure 2, A), which is fenestrated, allowed blood flow through the artery. In this way, the flow through the aberrant artery was preserved (control computed tomographic scans, Figure 2, $A$ and $B)$.

There were no significant variations of invasive radial pressure $(<10 \mathrm{~mm} \mathrm{Hg}$ ) between the two arms. The patient was discharged from the hospital 6 days later.

\section{Discussion}

Aberrant subclavian artery, also called arteria lusoria, was first described by Bayford in 1794. It is the most common form of aortic arch anomaly and has a reported incidence of $0.5 \%$ to $2 \%$. It results from regression of the right fourth aortic arch between the carotid and subclavian arteries. ${ }^{1}$

The association of aortic dissection and ARSA is rarely encountered; however, it has very important implications in treatment, either

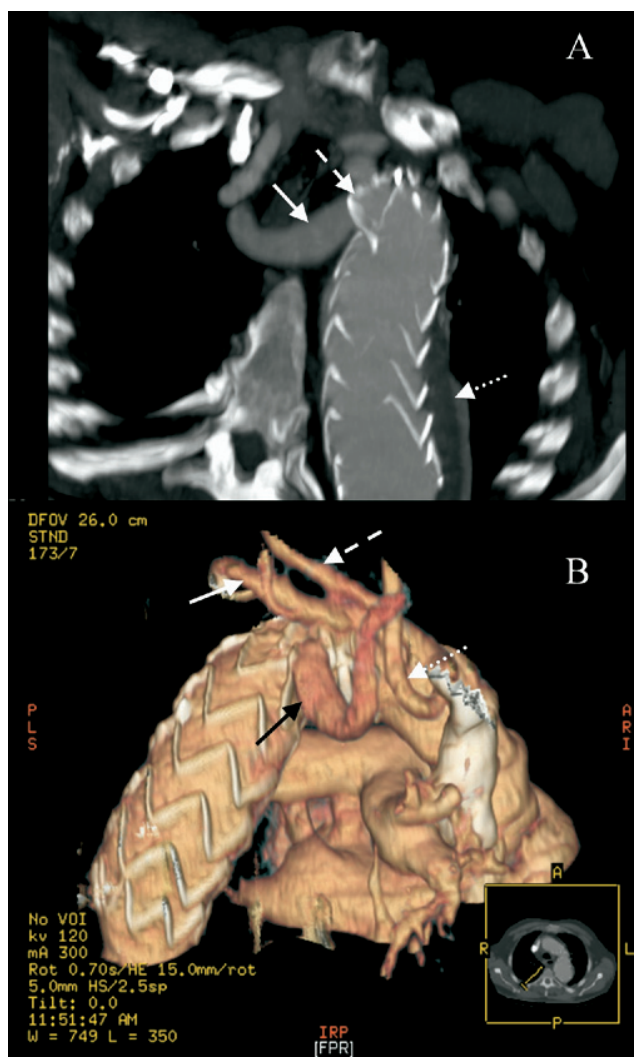

Figure 2. Contrast-enhanced slide of computed tomographic image. A, Coronal reconstruction of the distal aortic arch and thoracic aorta. The floppy FreeFlo straight portion (white dashed arrow) of the endograft preserved the patency of the ARSA (solid white arrow). The false lumen of the aneurysm was completely collapsed (dotted white arrow). B, Three-dimensional reconstruction of the aortic arch and origin of the supra-aortic vessels. Right common carotid artery (white dotted arrow), left common carotid artery (white dashed arrow), left subclavian artery (white arrow), and aberrant subclavian artery (black arrow).

surgical or endovascular. A number of surgical techniques have been proposed for treatment of this pathologic condition. These include transposition or bypass of the distal portion of the aberrant artery into the adjacent carotid artery, resection of the origin of the aneurysm from the descending thoracic aorta, and repair of the aortic dissection/aneurysm with the elephant trunk technique. ${ }^{2}$ The use of partial or total cardiopulmonary bypass, hypothermia, and circulatory arrest is normally necessary. Nevertheless, endovascular therapy has revolutionized this surgery. Complex open surgical procedures may be replaced by endovascular treatment, which is associated with a lower perioperative morbidity and mortality. ${ }^{3}$

In this case, the very high surgical risk of the patient led us to choose an endovascular treatment. We decided to use the Valiant system, which is a third-generation endoprosthesis designed specifically for the exclusion of thoracic aortic disease. ${ }^{4}$ Its floppy FreeFlo straight portion allowed us to deploy the endograft without 
occluding the ARSA and, therefore, without compromising either the right arm blood supply or the right vertebral artery flow.
2. Borst HG, Walterbusch G, Schaps D. Extensive aortic replacement using "elephant trunk" prosthesis. Thorac Cardiovasc Surg. 1983;31: $37-40$.

3. Kouchoukos NT, Masetti P. Aberrant subclavian artery and Kommerell aneurysm: surgical treatment with a standard approach. $J$ Thorac Cardiovasc Surg. 2007;133:888-92.

4. Brooks M, Loftus I, Morgan R, Thompson M. The Valiant thoracic endograft. J Cardiovasc Surg (Torino). 2006;47:269-78.

\section{Giant congenital left main coronary artery fistula to the superior vena cava in an adult patient with coronary artery disease}

\begin{abstract}
Ilias A. Kouerinis, MD, PhD, ${ }^{a}$ Martha Deligianni, MD, ${ }^{\mathrm{b}}$ Vassilios Maniatis, MD, $\mathrm{PhD},{ }^{\mathrm{b}}$ Ilias Elefteriadis, MD, ${ }^{b}$ Antonios Kourtesis, MD, ${ }^{a}$ and Nikolaos Michalopoulos, MD, Athens, Greece
\end{abstract}

1. Felson B, Cohen S, et al. Anomalous right subclavian artery. Radiology. 1950;54:340-9.

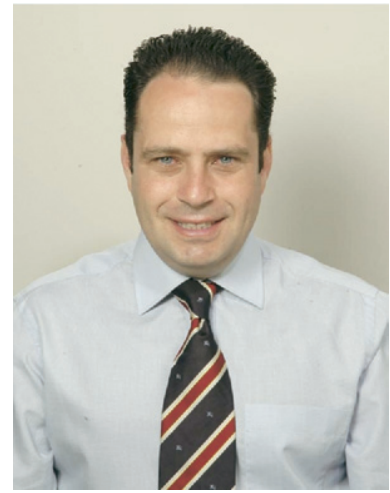

Dr Kouerinis
Supplemental material is available online.

I $\mathrm{t}$ is well established that coronary artery fistulae (CAFs) can cause dyspnea, fatigue, angina (7\%), and infarction (3\%) as a result of the coronary steal phenomenon. ${ }^{1}$ Nevertheless, there are few reports in which a CAF was associated with coronary artery disease (CAD), and even fewer studies have examined the consequences of this association on coronary hemodynamics and myocardial blood flow. ${ }^{2,3}$

We present the surgical treatment of a giant left main coronary artery (LMCA) fistula draining into the superior vena cava and coexistent $\mathrm{CAD}$, and we investigate the contribution of the coronary steal syndrome to this patient's symptoms.

\section{Clinical Summary}

A 62-year-old man was referred to our department with the diagnosis of an LMCA fistula and double-vessel disease (left anterior descending coronary artery, 85\%; circumflex artery, 80\%; Figures 1, E1, and E2). Oxymetry had shown an increased oxygen saturation of $84 \%$ at the lower segment of the superior vena cava with

From the Department of Cardiac Surgery, Aghia Sophia Children's Hospital, ${ }^{\mathrm{a}}$ Athens, Greece; and Iaso General Hospital, ${ }^{\mathrm{b}}$ Athens, Greece.

Received for publication June 12, 2007; accepted for publication July 5, 2007.

Address for reprints: Ilias Kouerinis, MD, PhD, 46 Doukissis Plakentias, Melissia, Athens, Greece (E-mail: ikouerinis@ hotmail.com).

J Thorac Cardiovasc Surg 2007;134:1057-8

$0022-5223 / \$ 32.00$

Copyright $\odot 2007$ by The American Association for Thoracic Surgery doi:10.1016/j.jtcvs.2007.07.004 high right ventricular filling pressures, and the Qp/Qs ratio was calculated at $1.4 / 1$.

Intraoperatively, after the opening of the pericardium, the fistula was easily identified (Figure 2), and cardiopulmonary bypass was initiated. After clamping the aorta, we provided retrograde cardioplegia to maintain arrest because significant shunt was noticed during the antegrade distribution. This problem was subsequently solved with digital pressure on the fistula, which was finally ligated $3 \mathrm{~cm}$ distally to the LMCA. We considered that it was too dangerous to attempt to ligate it more proximally to the LMCA because extreme calcification was palpated there. The check for step-up in oxygen saturation at the level of the right atrium and inferior vena cava proved negative, and we continued the operation by bypassing the first obtuse marginal and left anterior descending coronary artery with a saphenous vein graft and the left internal thoracic artery consecutively. The postoperative course was uneventful, and the patient was discharged home in good condition.

\section{Discussion}

Although only $40 \%$ of patients aged older than 20 years with CAF are asymptomatic, ${ }^{4}$ the exact role of CAFs as a nonatherosclerotic cause of myocardial ischemia has not been fully studied. Stierle and colleagues, ${ }^{5}$ using a sinus lactate study, demonstrated the role of the steal mechanism of CAFs, whereas Bamoshmoosh and associates $^{2}$ studied the reverse phenomenon, the redistribution of blood flow from the fistula to the coronary vessel. This so-called reverse steal phenomenon might offer an explanation as to how patients with severe CAD and remarkable shunt resulting from a CAF can survive so long.

Nevertheless, it still remains difficult to explain how a Qp/Qs ratio of 1.4 or more resulting exclusively from a big LMCA fistula is compatible with life, when we all know that the overall coronary blood flow in rest represents only $4 \%$ of systemic circulation. 